\title{
Proteins involved in cutaneous basal cell carcinoma development
}

\author{
MAGDALENA CIĄŻYŃSKA ${ }^{1}$, IGOR A. BEDNARSKI ${ }^{2}$, KAROLINA WÓDZ ${ }^{3}$, PAWEŁ KOLANO ${ }^{4}$, \\ JOANNA NARBUTT ${ }^{2}$, MICHAŁ SOBJANEK ${ }^{5}$, ANNA WOŹNIACKA ${ }^{6}$ and ALEKSANDRA LESIAK ${ }^{2}$ \\ ${ }^{1}$ Department of Proliferative Diseases, Regional Oncology Centre, Łódź 93-513; ${ }^{2}$ Department of Dermatology, Paediatric \\ Dermatology and Dermatological Oncology, Medical University of Łódź, Łódź 91-347; ${ }^{3}$ Department of Experimental \\ Immunology, Medical University of Łódź, Łódź 90-237; ${ }^{4}$ Department of General and Oncological Surgery, \\ Tomaszow Health Centre, Tomaszow Mazowiecki 97-200; ${ }^{5}$ Department of Dermatology, Venereology and \\ Allergy, Medical University of Gdansk, Gdansk 80-210; ${ }^{6}$ Department of Dermatology \\ and Venereology, Medical University of Łódź, Łódź 90-647, Poland
}

Received November 12,2017; Accepted April 12, 2018

DOI: $10.3892 / 01.2018 .9126$

\begin{abstract}
Basal cell carcinoma (BCC) is the most common skin malignancy type in the Caucasian population, with a continuously increasing incidence rate. The etiology of BCC remains unknown, but it appears to have a multifactorial origin resulting from intrinsic and extrinsic factors, including short-wavelength ultraviolet $\mathrm{B}$ radiation. The role of specific proteins in BCC that are known to be responsible for the regulation of cell division and are involved in skin aging, including transforming growth factor (TGF)- $\beta$, Smad2, matrix metalloproteinases (MMPs)-1, $-3,-8$ and -9 , cathepsin-K and progerin, remains unknown. The aim of the present study was to assess the mRNA and protein expression profile of samples with diagnosed nodular BCC (nBCC) compared with that of healthy skin samples collected from matched areas. The study group included 22 patients (10 men and 12 women; mean age, 59 years; range, $44-82$ years) with pathologically confirmed $\mathrm{nBCC}$, and 22 healthy volunteers (10 men and 12 women; mean age, 59 years; range, $43-78$ years) as a control group. The expression of the studied proteins was assessed in all samples by western blotting and reverse transcription-quantitative polymerase chain reaction analysis. Statistically significant increases in the expression of TGF- $\beta$, Smad2, cathepsin-K, progerin and MMP-1, $-3,-8$ and -9 were detected in skin biopsies with diagnosed nBCC compared with the control group, confirming the important role of these proteins in skin carcinogenesis.
\end{abstract}

Correspondence to: Dr Aleksandra Lesiak, Department of Dermatology, Paediatric Dermatology and Dermatological Oncology, Medical University of Łódź, 1/5 Kniaziewicza Street, Łódź 91-347, Poland

E-mail: aleksandra.lesiak@umed.lodz.pl

Key words: prostate cancer, prognosis, biomedical recurrence, gene expression, model

\section{Introduction}

Basal cell carcinoma (BCC) is the most common type of skin malignancy in the Caucasian population, with a continuously increasing incidence rate (1). Metastatic $\mathrm{BCC}$ is rare, but the tumor may occasionally grow aggressively, causing extensive tissue destruction, and the high incidence of this cancer represents a major public health concern (2). BCC most commonly occurs in adults, particularly in the elderly. However, in recent years it has become increasingly more common among younger adults, particularly women (3). BCC has several subtypes with distinct clinical and histological characteristics, with the nodular (nBCC) and superficial subtypes being the most common. nBCC, which accounts for $40-60 \%$ of BCCs, usually occurs in sun-exposed body areas, most commonly on the head, neck and upper extremities (4).

Despite extensive scientific research, the etiology of BCC remains unknown, but appears to have a multifactorial origin, which is the result of intrinsic and extrinsic factors (5). The development of BCC is clearly associated with sunburns, exposure to arsenic acid, pesticides, ionizing radiation and X-rays $(5,6)$. In addition, intrinsic constitutional factors, including gender, age and genetic predisposition, as well as pigment-associated traits, including fair skin, blond or red hair, light eye color, tendency to sunburn and poor tanning ability (Fitzpatrick's skin phototype I), have all been associated with a higher risk of $\mathrm{BCC}$ (7). However, the primary established risk factor in the development of $\mathrm{BCC}$, which is primarily responsible for cutaneous damage, is considered to be ultraviolet radiation (UVR), particularly short-wavelength UVB $(8,9)$. UVB radiation damages DNA and its repair system, which contributes to immune system alterations and resulting in genetic changes that may eventually lead to cancer formation (10). Furthermore, changes in the expression profile of specific proteins may be associated with skin carcinogenesis (11-16).

Transforming growth factor (TGF) $-\beta$ is a multifunctional polypeptide, the cytostatic and apoptotic functions of which restrain tissue growth. Abnormalities or complete loss of these functions lead to hyperproliferative disorders that are common 
in cancer (11). Furthermore, tumor cells may overproduce TGF- $\beta$ to create a local immunosuppressive environment that contributes to tumor growth (11). Thus, interest has been focused on elucidating the association between $\mathrm{BCC}$ and the expression of the proteins involved in the TGF- $\beta$ signaling pathway.

Matrix metalloproteinases (MMPs) are a family of proteolytic enzymes that have the ability to degrade collagen, elastin fibers and other proteins of connective tissue. Diseases characterized by degradation of extracellular matrix (ECM) proteins, including cancer, are also associated with upregulation of MMP expression, often previously induced by UVR $(12,13)$. It has not been clearly determined which of these molecules serve essential roles in the development and progression of BCC.

Cathepsin- $\mathrm{K}$ is a cysteine protease from the papain family with collagenolytic and elastinolytic properties. It was recently demonstrated that cathepsin- $\mathrm{K}$ is involved in the degradation of ECM in a number of organs, including the skin, which is an important step in tumor invasion and metastasis $(14,15)$. The role of this protein in cutaneous tumors has not been fully elucidated. Recent data indicate that overexpression of cathepsin- $\mathrm{K}$ is associated with the invasive and metastatic tendency of malignant melanoma. Its expression was also detected in squamous cell carcinoma (SCC) $(14,16)$. However, the expression of cathepsin-K in $\mathrm{BCC}$ has been reported in only a few studies $(14,15)$.

The mutant laminin A protein, also known as progerin, was identified in Hutchinson-Gilford syndrome, but elevated expression of this protein was also detected in naturally aging skin (17). To the best of our knowledge, there is no current information in the available literature regarding the expression of progerin in skin with BCC.

The aim of the present study was to assess the expression profile of selected proteins (TGF- $\beta$, Smad2, MMP-1, -3, -8 and -9 , cathepsin- $K$ and progerin) in samples with diagnosed $\mathrm{BCC}$ in comparison with control skin samples collected from matched areas using western blotting and reverse transcription-quantitative polymerase chain reaction (RT-qPCR) analysis.

\section{Materials and methods}

Patients. The study group consisted of 22 patients (10 men and 12 women; mean age, 59 years; range, 44-82 years) with histopathologically confirmed $\mathrm{nBCC}$, and 22 healthy volunteers (10 men and 12 women; mean age, 59 years; range, 43-78 years) as a control group. All patients with nBCC were diagnosed and treated at the Department of Dermatology and Venereology at the Medical University of Łódź (Łódź, Poland) between January 2013 and December 2015. All subjects signed written informed consent forms prior to enrolment to the study. The study design was approved by the local Ethics Committee (Komisja Bioetyczna przy Uniwersytecie Medycznym w Łodzi) and was conducted in accordance with the principles outlined in the Declaration of Helsinki. None of the examined subjects were HIV-positive, transplant recipients, suffering from other immunodeficiency disorders or receiving immunosuppressive treatment. Subjects in the healthy volunteer group who used indoor tanning or were overexposed to the sun during the last 2 months were excluded from the present study. Skin specimens in the control group were collected from the same areas as in the BCC group using the punch biopsy method (18). The tissues from all participants were immediately frozen in liquid nitrogen and stored at $-80^{\circ} \mathrm{C}$ until analysis.

Western blotting. For western blotting, skin specimens from all the participants were lysed in $0.25 \%$ Triton X-100 lysis buffer (Sigma-Aldrich; Merck KGaA, Darmstadt, Germany). Protein concentrations were measured using a bicinchoninic acid Protein Assay kit (Thermo Fisher Scientific, Inc., Waltham, MA, USA). A total of $50 \mu \mathrm{g}$ crude cell lysate protein per lane was separated via SDS-PAGE (10\% gel) and transfered to polyvinylidene difluoride membranes (EMD Millipore, Billerica, MA, USA). The membranes were incubated with 5\% skimmed milk with $0.1 \%$ Tween 20 (Sigma-Aldrich; Merck KGaA) overnight at $4^{\circ} \mathrm{C}$ with gentle agitation. Subsequently, the membranes were incubated for $1 \mathrm{~h}$, at room temperature, with gentle agitation with specific protein-conjugated primary antibodies purchased from Santa Cruz Biotechnology, Inc. (Dallas, TX, USA): Rabbit anti-TGF- $\beta 2$ (V, sc-90), goat anti-Smad (C-17, sc-6030), mouse anti MMP-1 (3B6, sc-21731), goat anti-MMP-3 (C-19, sc-6839), goat anti-MMP-8 (M-20, sc-8848), mouse anti-MMP-9 (2C3, sc-21733), mouse anti-cathepsin K (E-7), sc-48353) and pmouse anti-progerin (13A4D4, sc-81611), all at 1:200 dilution. Following three washes, the membranes were incubated for $1 \mathrm{~h}$ at room temperature, with gentle agitation, with horseradish peroxidase-conjugated secondary antibodies: Mouse anti-rabbit IgG (sc-2357), mouse anti-goat (sc-2354) and donkey anti-mouse IgG (sc-2318), all at 1:20.000 dilution (Santa Cruz Biotechnology, Inc.), and developed for $5 \mathrm{~min}$ in darkness using an enhanced chemiluminesence plus Western Blotting Detection kit (GE Healthcare, Chicago, IL, USA) and visualized with the ChemiImager system (ProteinSimple, San Jose, CA, USA). The bands corresponding to the proteins were digitalized using ChemiImager software Alpha Innotech 4400 (ProteinSimple). Quantitative densitometry analysis was performed using AlphaEaseFC Version 3.3.0. (ProteinSimple, San Jose, CA, USA).

$R T$ - $q P C R$. To determine the TGF- $\beta$, Smad2, MMP-1, MMP-3, MMP-8, MMP-9, CTSK (cathepsin-K) and LMNA (progerin) mRNA levels, RT-qPCR was employed. Total RNA was isolated using RNeasy Mini kit (Qiagen, Inc., Valencia, CA, USA). The RNA was treated with DNase I to remove contaminated genomic DNA and $2 \mu \mathrm{g}$ RNA was reverse-transcribed using the High-Capacity cDNA Reverse Transcription kit according to the manufacturer's protocol (Applied Biosystems; Thermo Fisher Scientific, Inc.). The expression of target gene mRNA, as well as the expression of the endogenous Actb ( $\beta$-actin) mRNA, was assessed using TaqMan ${ }^{\circledR}$ probes dyed with FAM and TaqMan ${ }^{\circledR}$ Gene Expression Master mix (Applied Biosystems; Thermo Fisher Scientific, Inc.). TaqMan ${ }^{\circledR}$ probes TGF- $\beta$ (Hs00234244_m1), Smad2 (Hs00183425), MMP-1 (Hs00899658_m1), MMP-3 (Hs00968305_m1), MMP-8 (Hs01029057_m1), MMP-9 (Hs00234579_m1), CTSK (Hs00166156_m1), LMNA (Hs00153462_m1) and hActb (Hs99999903_m1) detect only genomic DNA and span an exon junction. Gene-specific PCR products were measured using the 7900HT Fast Real-Time PCR system (Applied Biosystems; Thermo Fisher Scientific, Inc.) continuously during 40 cycles. The amplification conditions were as follows: 
Cathepsin-K
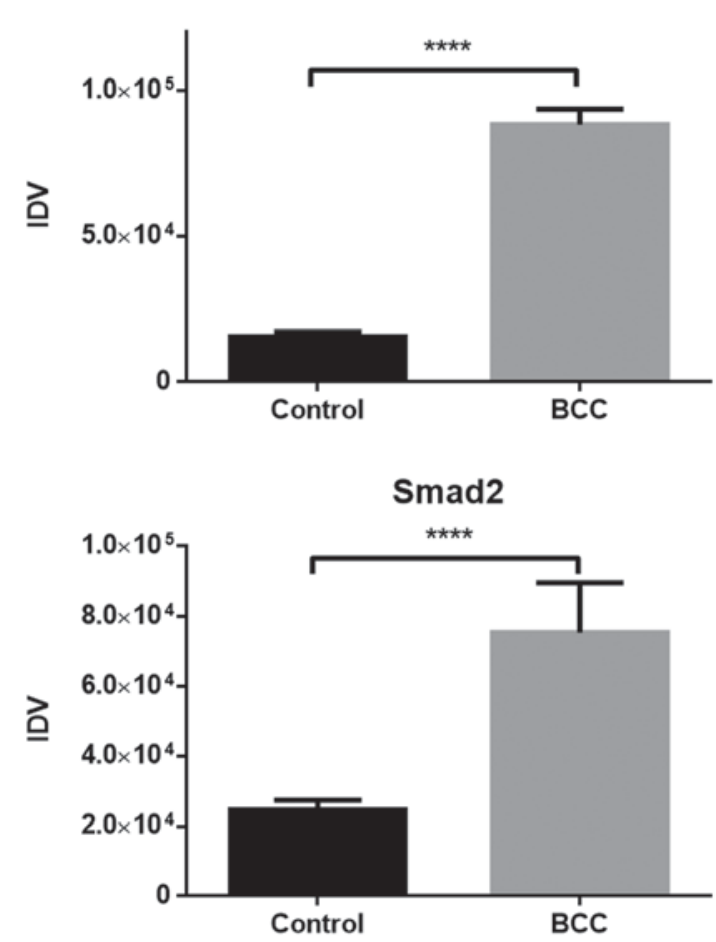

TGF- $\beta$
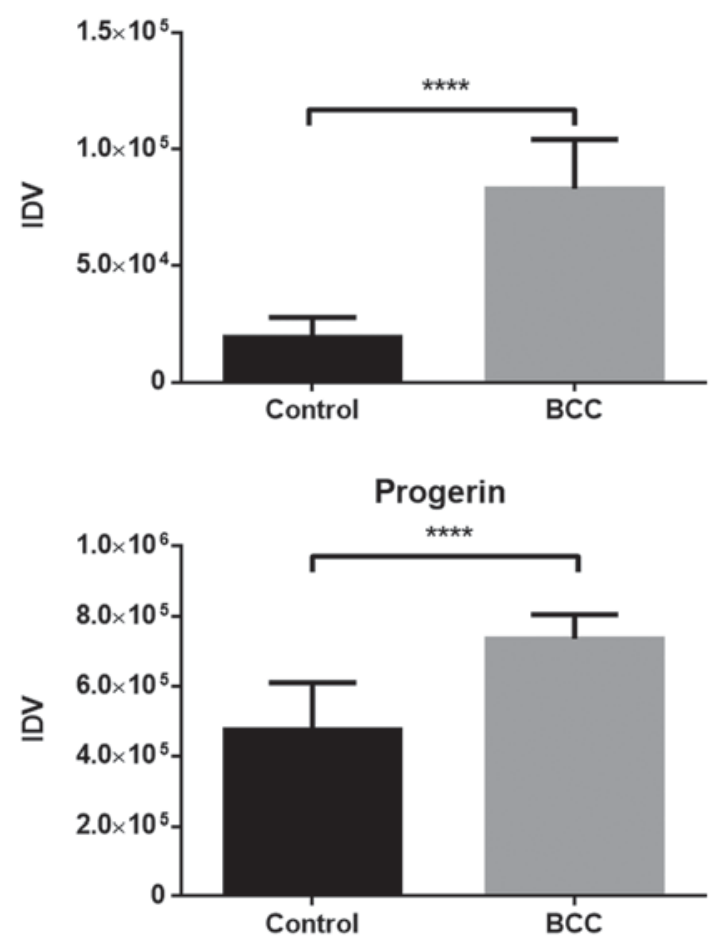

Figure 1. Data are presented as the median \pm interquartile range. The expression of selected proteins (cathepsin-K, TGF- $\beta$, Smad 2 and progerin) was evaluated using western blotting. The statistical significance of the differences was estimated with the Mann-Whitney U test due to the non-parametric distribution of the variables. BCC, basal cell carcinoma; TGF, transforming growth factor; IDV, integrated density values $\left({ }^{* * * * *} \mathrm{P}<0.0001\right)$.

Initial denaturation at $95^{\circ} \mathrm{C}$ for $20 \mathrm{sec}$, followed by 40 cycles of amplification at $95^{\circ} \mathrm{C}$ for $30 \mathrm{sec}$ and $60^{\circ} \mathrm{C}$ for $30 \mathrm{sec}$. Target gene expression was normalized to the endogenous expression of $\beta$-actin in each cDNA sample. Quantitative analysis of data was performed according to the $\Delta \Delta \mathrm{Cq}$ method (19).

Statistical analysis. Statistical analysis was performed using Statistica 12 (StatSoft, Inc., Tulsa, OK, USA) and GraphPad Prism 6 (GraphPad Software, Inc., La Jolla, CA, USA) software. The results were analyzed using the Mann-Whitney $\mathrm{U}$ test and $\mathrm{P}<0.05$ was considered to indicate a statistically significant difference. Results are presented as the medians + interquartile range of integrated density values (IDV) for protein expression and mean + standard deviations for mRNA expression.

\section{Results}

The expression of TGF- $\beta$, Smad2, MMP-1, -3, -8 and -9, cathepsin-K and progerin was assessed in all skin specimens. The expression levels of the analyzed proteins in skin biopsies with diagnosed BCC compared with the healthy control group are presented in Figs. 1 and 2, while representative western blots of the protein expression levels are presented in Fig. 3. All values in the figures are shown as the medians of IDV. The expression of all proteins evaluated with western blotting was demonstrated to be significantly higher in samples with diagnosed BCC compared with those from the control group $(\mathrm{P}<0.05)$, apart from MMP-8, for which the difference in expression between the two groups was insignificant $(\mathrm{P}=0.59)$.
The control group exhibited the highest expression level for progerin compared with other proteins. The median value of progerin expression was $4.75 \times 10^{5} \mathrm{IDV}$, while the value of expression in tumor tissues was $7.37 \times 10^{5}$ IDV, and those changes were statistically significant $(\mathrm{P}<0.05)$. MMP-1 exhibited the highest difference in protein expression between healthy and affected tissues.

A comparison of mRNA expression between the BCC and control group for analyzed samples that were evaluated by RT-qPCR is presented in Figs. 4 and 5. The mRNA level for all samples (TGF- $\beta$, Smad2, cathepsin-K, progerin and MMP-1, $-3,-8$ and -9$)$ was significantly higher in samples with diagnosed BCC compared with the healthy control group $(\mathrm{P}<0.05)$. MMP-3 exhibited the highest difference in mRNA expression between BCC and control cases.

\section{Discussion}

$\mathrm{BCC}$ remains the most common skin malignancy, with a rapidly increasing incidence rate worldwide (20). The exact mechanism underlying the pathogenesis of BCC has not been clearly determined. A possible, but unsupported explanation is the role of proteins that are involved in skin aging, as well as proteins that are responsible for the regulation of cell division in the skin, the dysregulation of which may lead to carcinogenesis. In the present study, the contribution of eight proteins to the development of $\mathrm{nBCC}$ was examined.

The role of TGF- $\beta$ in the development of multiple carcinomas has been previously confirmed. Available data regarding dysregulation of the TGF- $\beta /$ Smad pathway indicate its role in the development of pancreatic or breast cancer, as 

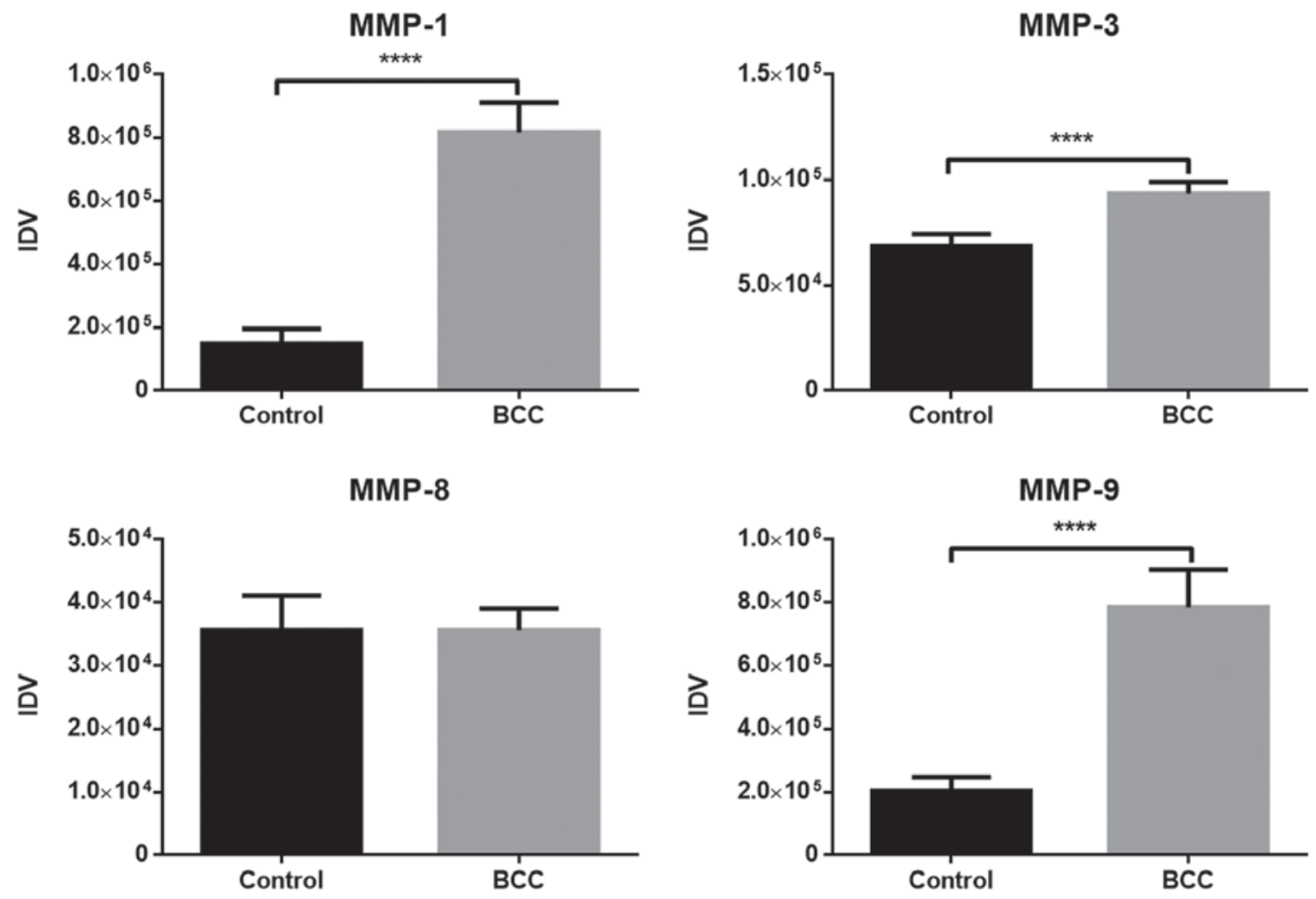

Figure 2. Data are presented as the median \pm interquartile range. The expression of selected proteins (MMP-1, $-3,-8$ and -9 ) was evaluated using western blotting. The statistical significance of the differences was estimated with the Mann-Whitney U test due to the non-parametric distribution of the variables. $\mathrm{BCC}$, basal cell carcinoma; MMP, matrix metalloproteinase; IDV, integrated density values $\left({ }^{* * * * *} \mathrm{P}<0.0001\right)$.

well as various skin cancer types, including melanoma and SCC (21). However, the role of this cytokine and its effector proteins in BCC development remains unclear (21).

Cui et al (22) confirmed that the role of TGF- $\beta$ changes as the carcinogenic process evolves. TGF- $\beta$ in normal tissues inhibits cell proliferation and is able to block the cell cycle in the $G_{1}$ phase, whereas in tumor tissues it is involved in the progression of carcinogenesis and metastatic spread (23-26). This phenomenon is referred to as the TGF- $\beta$ paradox $(24,25)$.

Schmid et al (27) compared the mRNA expression of all three isoforms of TGF- $\beta$ (TGF- $\beta 1$, TGF- $\beta 2$ and TGF- $\beta 3$ ) and TGF- $\beta$ type II receptor (T $\beta$ R II) in normal human skin and BCC tissue, and observed increased TGF- $\beta 1$ and T $\beta \mathrm{R}$ II. Tumor tissues of all BCCs exhibited reduced TGF- $\beta 3$ mRNA and protein expression, compared with normal interfollicular epidermis; whereas, the expression of TGF- $\beta 1$ mRNA was notably reduced in tumor tissues and normal skin epithelia (27). The data were confirmed by research performed by Gambichler et al (28) and Furue et al (29).

Gambichler et al (28) revealed that the mRNA levels of TGF- $\beta /$ Smad observed in healthy control skin did not significantly differ from the TGF- $\beta /$ Smad levels detected in non-lesioned skin of patients with previously diagnosed BCC. As opposed to previous studies, significant mRNA overexpression of TGF- $\beta 1, \mathrm{Smad} 3$ and $\mathrm{Smad} 7$ was observed in BCC compared with non-lesional skin. These data on TGF- $\beta$ are consistent with those of the present study, which revealed a significant increase of TGF- $\beta$ expression at the mRNA and protein levels in skin biopsies with diagnosed BCC compared with healthy skin biopsies collected from the control group. Similar results were obtained in the results of the present study regarding Smad2. Thus, this data indicates a possible role of TGF- $\beta / \mathrm{Smad}$ signaling in the pathogenesis of BCC.

MMPs are produced by healthy cells, as well as cancer cells. Overexpression of certain MMPs in pancreatic, gastric, lung and breast cancer is associated with a more aggressive disease course and higher propensity for invasion and metastasis (30). Altered MMP activity in cancer cells leads to excessive activation of extracellular proteolysis. MMP-9 serves the most essential role in $\mathrm{BCC}$ progression. This protein degrades collagen and elastin fibers, enhancing the ability of cancer cells to migrate beyond the tumor (31). Increased expression of MMP-9 is associated with the extent of tumor progression (32-34). MMP-1 and MMP-3 are also involved in the degradation of collagens, promoting rapid tumor development. The present study revealed significant differences in the level of mRNA and protein expression of MMP-1, -3 and -9 between healthy skin biopsies and in skin biopsies with diagnosed BCC.

Wyględowska-Kania et al (35) reported a significant increase in the number of MMP-1 gene copies in all BCC samples. The available literature confirms that the expression of MMP-9 was significantly higher in BCC samples compared with that in unaffected skin. Monhian et al (36) stated that the expression levels of MMP-1 and MMP-9 were consistently elevated in the peritumoral tissue compared with skin from more distal sites. Varani et al (37) analyzed tissues from 54 histologically confirmed BCCs of the skin using immunochemical procedures. In normal skin, the activity levels of 


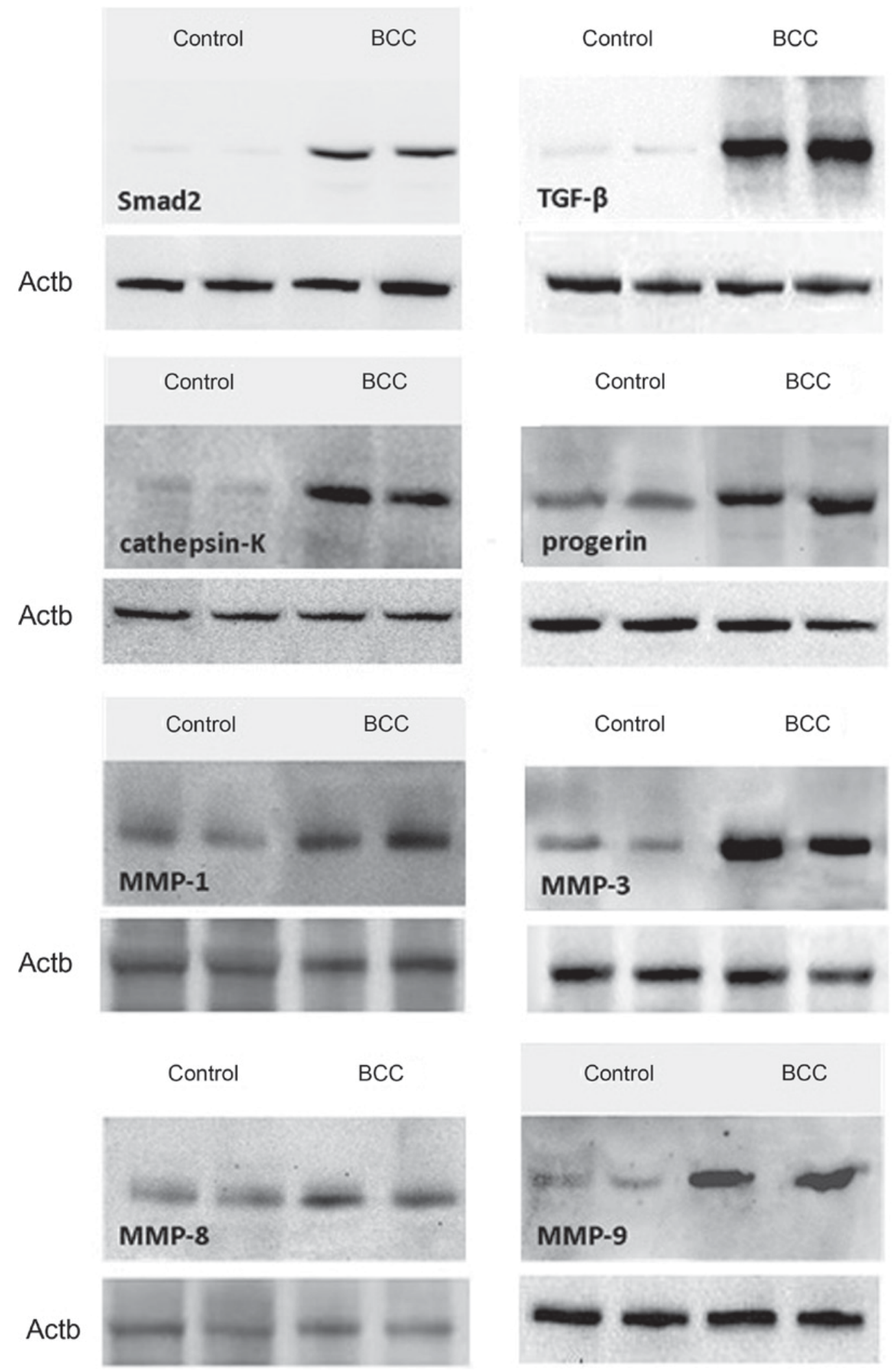

Figure 3. Representative western blots of photodamage-related proteins in skin samples from the control group and patients with BCC in reference to Actb. $\mathrm{BCC}$, basal cell carcinoma; Actb, $\beta$-actin; MMP, matrix metalloproteinase; TGF, transforming growth factor.

MMP-1 and MMP-9 were low to undetectable. By contrast, the expression of these proteins was increased in tumor tissues.

The results of the current study demonstrated detectable expression of MMPs in skin samples with diagnosed BCC, as well as healthy skin. Tumor-affected tissues exhibited significantly increased expression of MMP-1, -3 and -9 at the mRNA and protein levels compared with unaffected tissues. These data confirm the important role of this protein in carcinogenesis, and these changes in expression may be useful in the diagnosis of tumor-affected tissues. 


\section{Cathepsin-K}

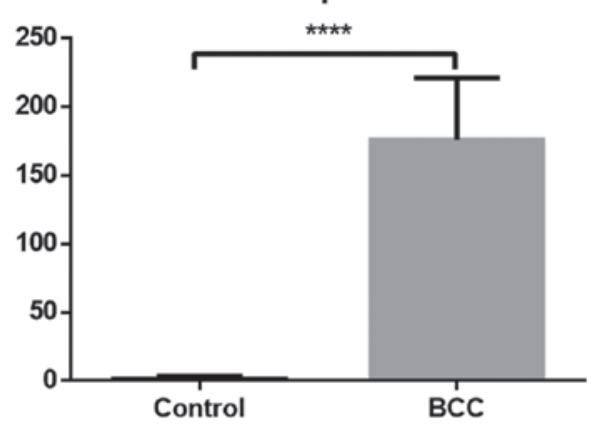

Smad2

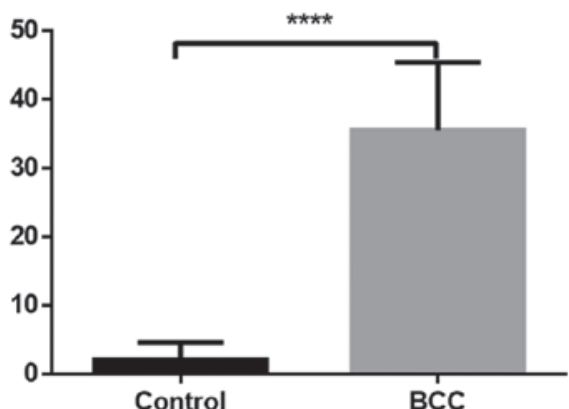

TGF- $\beta$

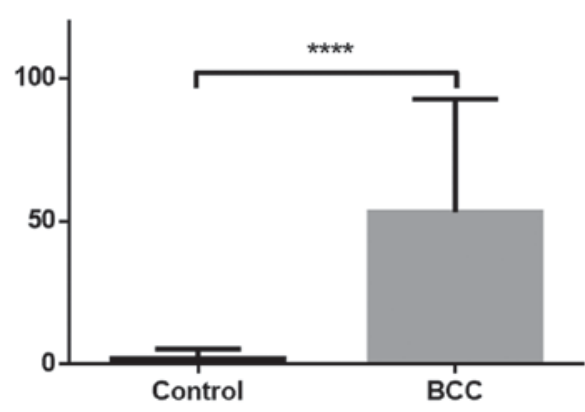

Progerin

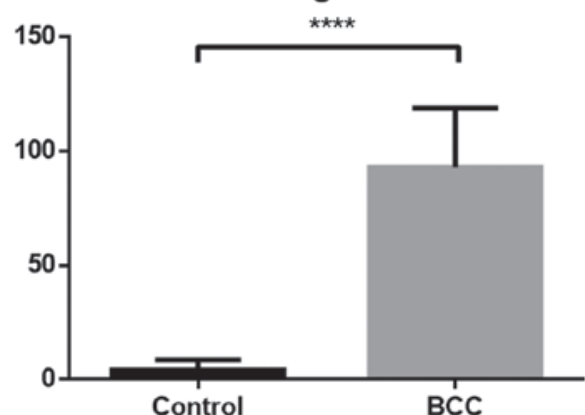

Figure 4. Data are presented as the means \pm standard deviations. The mRNA expression of cathepsin-K, TGF- $\beta$, Smad 2 and progerin was evaluated using reverse transcription-quantitative polymerase chain reaction analysis. The statistical significance of the differences was estimated with the Mann-Whitney $\mathrm{U}$ test due to the non-parametric distribution of the variables. BCC, basal cell carcinoma; TGF, transforming growth factor $\left({ }^{* * * *} \mathrm{P}<0.0001\right)$.

MMP-1

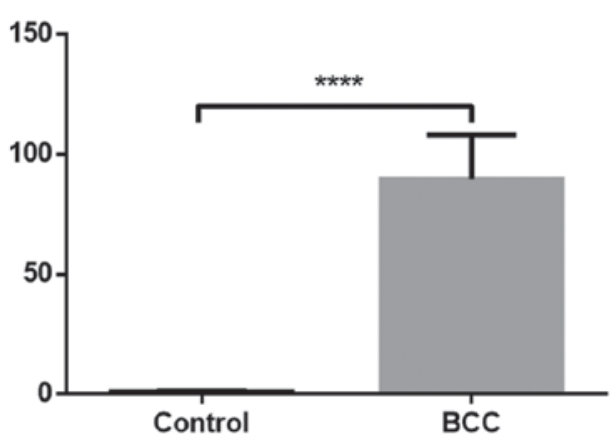

MMP-8

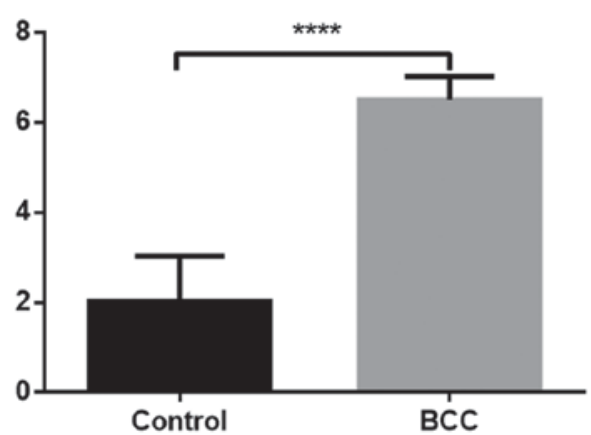

MMP-3

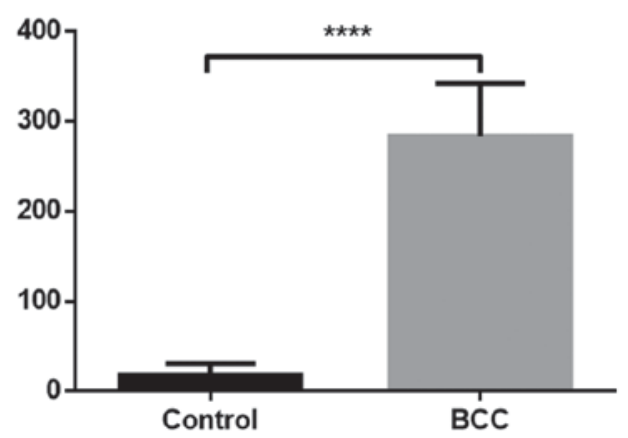

MMP-9

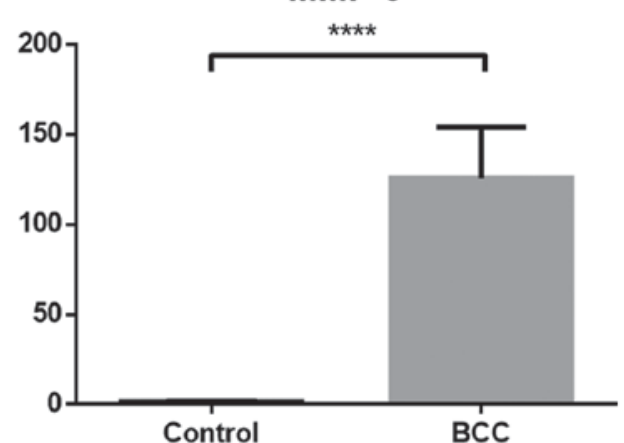

Figure 5. Data are presented as means \pm standard deviations. The mRNA expression of MMP-1, $-3,-8$ and -9 was evaluated using reverse transcription-quantitative polymerase chain reaction analysis. The statistical significance of the differences was estimated with the Mann-Whitney U test due to the non-parametric distribution of the variables. BCC, basal cell carcinoma; MMP, matrix metalloproteinase $\left({ }^{* * * *} \mathrm{P}<0.0001\right)$.

Previous analysis of MMP-8 in breast cancer patients indicated that expression of this MMP by breast tumors is associated with a lower incidence of lymph node metastasis (38). On this basis, MMP-8 may be a tumor protective factor, 
which also has the ability to reduce the metastatic potential of malignant cells in humans (38). In the present study, significant overexpression of MMP-8 mRNA was observed in BCC, which has previously been observed in human SCC (39).

However, the western blot studies in the present study revealed only a slight increase in MMP- 8 protein in the tumor tissue. This discrepancy in MMP-8 expression at the mRNA and protein levels may be explained by the fact that RT-qPCR is a significantly more sensitive technique that is able to document the slightest evidence of gene expression. However, western blot analysis is important, since it reveals whether the transcript is translated and functionally available. Furthermore, the protein may be translated at normal levels as observed in the control group, but degraded at an abnormal level as observed in the BCC group, which may also be a plausible explanation. To the best of our knowledge, these results were the first to demonstrate the expression of MMP-8 in BCC tissues by applying RT-PCR and western blot analysis.

Cathepsin-K serves an important role in homeostasis of dermal ECM by maintaining the balance between protein synthesis and proteolysis $(40,41)$. It was previously confirmed that cathepsin- $\mathrm{K}$ is involved in various processes associated with photodestruction, scarring and carcinogenesis (40). However, the expression of cathepsin-K in BCC has not been well characterized. To the best of our knowledge, there are only few published studies that have investigated the expression of cathepsin-K in BCC $(14,15)$.

In a study performed by Quintanilla-Dieck et al (14), it was demonstrated that cathepsin-K immunostaining has distinct staining patterns for melanoma and non-melanoma skin cancer (NMSCs). Unlike melanoma, SCCs and BCCs do not or only focally express this protein. Weak focal expression of cathepsin-K within tumor cells was detected in only $2 / 3$ cases of diagnosed $\mathrm{BCC}$, while in the remaining $\mathrm{BCC}$ samples no staining was observed. However, in all samples with BCC, there was strong expression in the peritumoral stroma, which was markedly more intense compared with that in the peritumoral stroma surrounding certain melanomas. It was suggested that stromal cathepsin-K expression may promote invasion of NMSCs and contribute to bone invasion by activation of osteoclasts at the invasion front, whereas when these tumor cells encounter an invasion barrier in which cathepsin-K is not induced, they may fail to invade and produce metastasis. This may explain why NMSCs, particularly BCC, are less prone to metastasis compared with melanoma.

Ishida et al (15) assessed cathepsin-K expression by immunohistochemical methods in a group of 50 consecutive operative cases of BCC and compared the results with the expression of this protein in healthy skin. In normal skin, cathepsin-K expression was observed in the stratum corneum, mature sebaceous cells and outer root sheath of the hair follicles. Cathepsin-K was expressed in the tumor cells of all $\mathrm{BCC}$ cases. Increased levels of cathepsin-K expression may contribute to tumor invasion of $\mathrm{BCC}$, similar to malignant melanoma. Data from these trials obtained using immunohistochemistry indicate that the expression of cathepsin-K protein is altered in BCC $(14,15)$. The present study aimed to investigate the mRNA as well as protein expression levels of cathepsin-K in patients with $\mathrm{BCC}$ and healthy controls.
The expression of cathepsin-K was detected in all analyzed samples. This expression was the weakest in healthy skin and was significantly higher in BCC compared with unaffected skin.

Lamins are components of nuclear proteins that affect essential processes in the nucleus, including transcription and replication. In previous studies, reduced or no expression of the normal form of lamin A was identified to be associated with a rapid growth rate of the tumor (42-44). By contrast, another study demonstrated the presence of substantial amounts of lamin A in proliferating BCC cells (45). In recent years, increasing efforts have been focused on evaluating the role of progerin (mutated form of lamin A) in photoaging and mechanisms leading to carcinogenesis. Scaffidi and Misteli (46) revealed a contribution of progerin to the photoaging process. This protein is resistant to degradation induced by MMPs. McClintock et al (17) analyzed the expression of progerin in skin biopsies from unaffected individuals with a wide age range (newborn to 97 years old). They revealed that progerin mRNA may be detected at uniform levels by RT-PCR analysis in all tissue samples, but the protein appears to accumulate with increasing age. Their findings revealed that progerin expression is a biomarker of normal cellular aging, and may be associated with terminal differentiation and senescence in elderly individuals. However, although the role of progerin expression in relation to skin aging has been investigated, to the best of our knowledge, the present study is the first systematic study to investigate the expression of progerin protein in human nBCC using RT-qPCR as well as western blotting.

In the present study, all analyzed skin biopsies exhibited progerin expression at the mRNA and protein level. Furthermore, a significant increase in expression was observed in biopsies with diagnosed BCC compared with healthy skin samples. The accumulation of progerin may contribute to the dysregulation of cell proliferation that results in carcinogenesis, which may explain the overexpression of progerin in $\mathrm{BCC}$ tissues.

In summary, the results of the present study were the first to demonstrate enhanced expression of progerin in BCC tissue. Furthermore, the comparison of the expression of TGF- $\beta$, Smad2, cathepsin-K and MMP-1, $-3,-8$ and -9 between $\mathrm{BCC}$ lesions and healthy control skin samples confirms the important role of these proteins in skin carcinogenesis. These findings may enable a better understanding of the mechanisms underlying BCC development and provide new insight into the development of novel therapeutic strategies for BCC. Thus far, therapy with inhibitor proteins has been successfully used in the treatment of bone loss associated with osteoporosis, as well as in an experimental study on breast cancer cell invasion $(38,47,48)$. The present study investigated the protein expression pattern in BCC, and assessed its usefulness as a potential diagnostic marker and molecular therapy target for the treatment of common skin cancers, including BCC. Further studies are required to verify the effectiveness of topical administration of protein inhibitors as a treatment for BCC. However, the validity of the present data may be limited, as only the nBCC subtype was examined. Further studies are required to investigate the effect of various proteins on other BCC subtypes. 


\section{Acknowledgements}

Not applicable.

\section{Funding}

The present study was funded by the National Centre of Science (grant no. 2012/05/B/NZ5/01885) and the Medical University of Łódź (grant nos. 503/5-064-01/503-01 and 503/1-152-01/503-11-002).

\section{Availability of data and materials}

The datasets used and analyzed during the current study are available from the corresponding author on reasonable request.

\section{Authors' contributions}

$\mathrm{PK}, \mathrm{JN}$ and AW conceived and designed the experiments. $\mathrm{KW}, \mathrm{MS}, \mathrm{AL}$ and MC performed the experiments. MC wrote the manuscript with support from MS. IAB assisted in interpreting the results and worked on the manuscript. AL supervised the project. All authors discussed the results and commented on the manuscript. All authors read and approved the final manuscript.

\section{Ethics approval and consent to participate}

All subjects signed written informed consent forms prior to enrolment to the study. The study design was approved by the local Ethics Committee (Komisja Bioetyczna przy Uniwersytecie Medycznym w Łodzi) and was conducted in accordance with the principles outlined in the Declaration of Helsinki.

\section{Patient consent for publication}

Not applicable.

\section{Competing interests}

The authors declare that they have no competing interests.

\section{References}

1. Lesiak A, Slowik-Rylska M, Rogowski-Tylman M, Sysa-Jedrzejowska A, Norval M and Narbutt J: Risk factors in Central Poland for the development of superficial and nodular basal cell carcinomas. Arch Med Sci 6: 270-275, 2010.

2. Tilli CM, Van Steensel MA, Krekels GA, Neumann HA and Ramaekers FC: Molecular aetiology and pathogenesis of basal cell carcinoma. Br J Dermatol 152: 1108-1124, 2005.

3. Miller DL and Weinstock MA: Nonmelanoma skin cancer in the United States: Incidence. J Am Acad Dermatol 30: 774-778, 1994.

4. Daya-Grosjean L and Couvé-Privat S: Sonic hedgehog signaling in basal cell carcinomas. Cancer Lett 225: 181-192, 2005.

5. Dessinioti C, Antoniou C, Katsambas A and Stratigos AJ: Basal cell carcinoma: What's new under the sun. Photochem Photobiol 86: 481-491, 2010.

6. Corona R, Dogliotti E, D'Errico M, Sera F, Iavarone I, Baliva G, Chinni LM, Gobello T, Mazzanti C, Puddu P and Pasquini P: Risk factors for basal cell carcinoma in a Mediterranean population: Role of recreational sun exposure early in life. Arch Dermatol 137: 1162-1168, 2001.
7. Green A, Battistutta D, Hart V, Leslie D and Weedon D: Skin cancer in a subtropical Australian population: Incidence and lack of association with occupation. The Nambour Study Group. Am J Epidemiol 144: 1034-1040, 1996.

8. Gallagher RP and Lee TK: Adverse effects of ultraviolet radiation: A brief review. Prog Biophys Mol Biol 92: 119-131, 2006.

9. Oberyszyn TM: Non-melanoma skin cancer: Importance of gender, immunosuppressive status and vitamin D. Cancer Lett 261: 127-136, 2008

10. Lupi O: Correlations between the Sonic Hedgehog Pathway and basal cell carcinoma. Int J Dermatol 46: 1113-1117, 2007.

11. Siegel PM and Massagué J: Cytostatic and apoptotic actions of TGF-beta in homeostasis and cancer. Nat Rev Cancer 3: 807-820, 2003.

12. Yucel T, Mutnal A, Fay K, Fligiel SE, Wang T, Johnson T, Baker SR and Varani J: Matrix metalloproteinase expression in basal cell carcinoma: Relationship between enzyme profile and collagen fragmentation pattern. Exp Mol Pathol 79: 151-160, 2005.

13. Poswar FO, Fraga CA, Farias LC, Feltenberger JD, Cruz VP, Santos SH, Silveira CM, de Paula AM and Guimarães AL: Immunohistochemical analysis of TIMP-3 and MMP-9 in actinic keratosis, squamous cell carcinoma of the skin, and basal cell carcinoma. Pathol Res Pract 209: 705-709, 2013.

14. Quintanilla-Dieck MJ, Codriansky K, Keady M, Bhawan J and Rünger TM: Cathepsin K in melanoma invasion. J Invest Dermatol 128: 2281-2288, 2008.

15. Ishida M, Kojima F and Okabe H: Cathepsin-K expression in basal cell carcinoma. J Eur Acad Dermatology Venereol 27: e128-e130, 2013.

16. Yan X, Takahara M, Xie L, Oda Y, Nakahara T, Uchi H, Takeuchi S, Tu Y, Moroi Y and Furue M: Stromal expression of cathepsin-K in squamous cell carcinoma. J Eur Acad Dermatology Venereol 25: 362-365, 2011.

17. McClintock D, Ratner D, Lokuge M, Owens DM, Gordon LB, Collins FS and Djabali K: The mutant form of lamin A that causes Hutchinson-Gilford progeria is a biomarker of cellular aging in human skin. PLoS One 2: e1269, 2007.

18. Zuber TJ: Punch biopsy of the skin. Am Fam Physician 65: 1155-1158, 1161-1162, 1164, 2002.

19. Livak KJ and Schmittgen TD: Analysis of relative gene expression data using real-time quantitative PCR and the 2(-Delta Delta C(T)) method. Methods 25: 402-408, 2001.

20. Ting PT, Kasper R and Arlette JP: Metastatic basal cell carcinoma: Report of two cases and literature review. J Cutan Med Surg 9: 10-15, 2005.

21. Han G and Wang XJ: Roles of TGF $\beta$ signaling Smads in squamous cell carcinoma. Cell Biosci 2011; 1: 41, 2011.

22. Cui W, Fowlis DJ, Bryson S, Duffie E, Ireland H, Balmain A and Akhurst RJ: TGFbetal inhibits the formation of benign skin tumors, but enhances progression to invasive spindle carcinomas in transgenic mice. Cell 86: 531-542, 1996.

23. Stalińska L and Ferenc T: The role of TGF-beta in cell cycle regulation. Postepy Hig Med Dosw (Online) 59: 441-449, 2005 (In Polish).

24. Bierie B and Moses HL: Tumour microenvironment: TGFbeta: The molecular Jekyll and Hyde of cancer. Nat Rev Cancer 6: 506-520, 2006.

25. Hata A, Shi Y and Massagué J: TGF-beta signaling and cancer: Structural and functional consequences of mutations in Smads. Mol Med Today 4: 257-262, 1998.

26. Li AG, Lu SL, Han G, Kulesz-Martin M and Wang XJ: Current view of the role of transforming growth factor beta 1 in skin carcinogenesis. J Investig Dermatol Symp Proc 10: 110-117, 2005.

27. Schmid P, Itin P and Rufli T: In situ analysis of transforming growth factors-beta (TGF-beta 1, TGF-beta 2, TGF-beta 3) and TGF-beta type II receptor expression in basal cell carcinomas. $\mathrm{Br}$ J Dermatol 134: 1044-1051, 1996.

28. Gambichler T, Skrygan M, Kaczmarczyk JM, Hyun J, Tomi NS, Sommer A, Bechara FG, Boms S, Brockmeyer NH, Altmeyer P and Kreuter A: Increased expression of TGF-beta/Smad proteins in basal cell carcinoma. Eur J Med Res 12: 509-514, 2007.

29. Furue M, Kato M, Nakamura K, Nashiro K, Kikuchi K, Okochi H, Miyazono K and Tamaki K: Dysregulated expression of transforming growth factor beta and its type-I and type-II receptors in basal-cell carcinoma. Int J Cancer 71: 505-509, 1997.

30. Witek K, Goździalska A and Jaśkiewicz J: Metaloproteinazy jako nowy wskaźnik diagnostyczny nowotworów skóry. Stan skóry wykładnikiem stanu zdrowia. (red.) Anna Goździalska, Jerzy Jaśkiewicz. Kraków: Oficyna Wydawnicza AFM: 19-29, 2012. 
31. Śliwowska I and Kopczyński Z: Metaloproteinazy macierzy zewnątrzkomórkowej-charakterystyka biochemiczna i kliniczna wartość oznaczania u chorych na raka piersi. Wsp Onkol 9: 327-335, 2005 (In Polish)

32. Lukaszewicz-Zajac M, Mroczko B and Szmitkowski M: The significance of metalloproteinases and their inhibitors in gastric cancer. Postepy Hig Med Dosw (Online) 63: 258-265, 2009 (In Polish).

33. Groblewska M, Mroczko B and Szmitkowski M: The role of selected matrix metalloproteinases and their inhibitors in colorectal cancer development. Postepy Hig Med Dosw (Online) 64: 22-30, 2010 (In Polish).

34. Kwiatkowski P: The role of matrix metalloproteinases in tumour invasion. Pol Ann Med: 43-50, 2008.

35. Wyględowska-Kania M, Gola J, Fila-Daniłow A, Wcisło-Dziadecka D, Brzezińska-Wcisło L and Mazurek U: Molecular studies of non-melanoma skin cancers. Borgis-Postępy Nauk Med: 752-757, 2012.

36. Monhian N, Jewett BS, Baker SR and Varani J: Matrix metalloproteinase expression in normal skin associated with basal cell carcinoma and in distal skin from the same patients. Arch Facial Plast Surg 7: 238-243, 2005.

37. Varani J, Hattori Y, Chi Y, Schmidt T, Perone P, Zeigler ME, Fader DJ and Johnson TM: Collagenolytic and gelatinolytic matrix metalloproteinases and their inhibitors in basal cell carcinoma of skin: Comparison with normal skin. Br J Cancer 82: 657-665, 2000.

38. Gutiérrez-Fernández A, Fueyo A, Folgueras AR, Garabaya C, Pennington CJ, Pilgrim S, Edwards DR, Holliday DL, Jones JL, Span PN, et al: Matrix metalloproteinase-8 functions as a metastasis suppressor through modulation of tumor cell adhesion and invasion. Cancer Res 68: 2755-2763, 2008.

39. Goździalska Anna, Gawędzka Anna, Brzewski Paweł and Wojas-Pelc Anna JJ: Skin cancer diagnosis based on the determination of the expression metalloproteinases. Interdescyplinarne aspekty Nauk o zdrowiu: 41-56, 2010.
40. Rao Q, Wang Y, Xia QY, Shi SS, Shen Q, Tu P, Shi QL, Zhou XJ and Wu B: Cathepsin-K in the immunohistochemical diagnosis of melanocytic lesions. Int J Clin Exp Pathol 7: 1132-1139, 2014.

41. Zheng Y, Chen H, Lai W, Xu Q, Liu C, Wu L and Maibach HI Cathepsin D repairing role in photodamaged skin barrier. Skin Pharmacol Physiol 28: 97-102, 2015.

42. Prokocimer M, Davidovich $M$, Nissim-Rafinia $M$, Wiesel-Motiuk N, Bar DZ, Barkan R, Meshorer E and Gruenbaum Y: Nuclear lamins: Key regulators of nuclear structure and activities. J Cell Mol Med 13: 1059-1085, 2009.

43. Venables RS, McLean S, Luny D, Moteleb E, Morley S, Quinlan RA, Lane EB and Hutchison CJ: Expression of individual lamins in basal cell carcinomas of the skin. Br J Cancer 84: 512-519, 2001.

44. Oguchi M, Sagara J, Matsumoto K, Saida T and Taniguchi S: Expression of lamins depends on epidermal differentiation and transformation. Br J Dermatol 147: 853-858, 2002.

45. Tilli CM, Ramaekers FC, Broers JL, Hutchison CJ and Neumann HA: Lamin expression in normal human skin, actinic keratosis, squamous cell carcinoma and basal cell carcinoma. $\mathrm{Br}$ J Dermatol 148: 102-109, 2003.

46. Scaffidi P and Misteli T: Lamin A-dependent nuclear defects in human aging. Science 312: 1059-1063, 2006.

47. Lin W, Huang J, Yuan Z, Feng S, Xie Y and Ma W: Protein kinase $C$ inhibitor chelerythrine selectively inhibits proliferation of triple-negative breast cancer cells. Sci Rep 7: 2022, 2017.

48. Baud'huin M, Lamoureux F, Jacques C, Rodriguez Calleja L, Quillard T, Charrier C, Amiaud J, Berreur M, Brounais-LeRoyer B, Owen R, et al: Inhibition of BET proteins and epigenetic signaling as a potential treatment for osteoporosis. Bone 94: 10-21, 2017. 